\title{
ANÁLISE DA DISTRIBUIÇÃO DE TERRAS NOS ASSENTAMENTOS RURAIS DA METADE SUL DO RIO GRANDE DO SUL: A PERSPECTIVA DE UMA SUSTENTABILIDADE COMPATÍVEL
}

\section{ANALYSIS OF DISTRIBUTION OF LAND IN RURAL SETTLEMENTES OF THE SOUTH HALF OF RIO GRANDE DO SUL: THE PERSPECTIVE OF A SUSTAINABILITY \\ COMPATIBLE}

\author{
Jefferson Marçal da Rocha \\ Universidade Federal do Pampa - São Gabriel - RS - Brasil \\ Francis Casagranda Zanella \\ Universidade Federal do Pampa - São Gabriel - RS - Brasil \\ Rafael Cabral Cruz \\ Universidade Federal do Pampa - São Gabriel - RS - Brasil
}

\begin{abstract}
Resumo: Este artigo analisa o processo de distribuição de terras e as principais estratégias produtivas adotadas nos assentamentos rurais da Metade Sul do Rio Grande do Sul nos últimos anos, considerando a compatibilidade socioambiental com o tamanho dos lotes. Questionários e entrevistas semiestruturadas foram realizadas com agentes qualificados relacionados à questão agrária na região, além da análise de documentos e bibliografias. A região estudada teve, em sua formação, processos de transformação ambiental que constituíram o bioma Pampa, que é fruto da coevolução entre os seres humanos e a biota, desde a ocupação do território pelos povos da Tradição Umbu, que introduziram o manejo do fogo para a caça. Com a chegada dos europeus e da pecuária extensiva, o sistema se transformou, por meio de um processo de adaptação socioambiental, resultando na forma atual do bioma, com campos de alta biodiversidade. No decorrer do século XX, esse sistema sofreu forte influência do conjunto de estratégias e técnicas produtivas agrícolas ligadas à expansão do agronegócio na região, que provocaram perdas significativas da biodiversidade do bioma. Na década de 1980, a partir de pressões sociais pela reforma agrária na região, surgiram políticas de assentamentos com a perspectiva de estimular uma estratégia
\end{abstract}

Redes (St. Cruz Sul, Online), v. 20, $\mathrm{n}^{\circ} 2$, p. 213 - 235, maio./ago. 
para o desenvolvimento da Metade Sul. Nesses loteamentos, as terras foram divididas em módulos rurais que variam entre 10 a 30 hectares. Os resultados demonstram que o método utilizado na distribuição, aliado a práticas agrícolas convencionais, não garantirá a preservação ambiental do bioma e não viabilizará a reprodução socioeconômica das famílias a médio e longo prazo. A partir desta análise, fica evidente que os lotes distribuídos, condicionados à trama socioeconômica e cultural já existente na região, levarão ao aprofundamento da perda da biodiversidade e das desigualdades sociais. Esse processo só poderá ser revertido com métodos coerentes de distribuição e a prática de uma agricultura compatível, nas bases do desenvolvimento rural sustentável.

Palavras-chave: Desenvolvimento rural sustentável. Reforma agrária. Políticas públicas.

Abstract: This article analyzes the process of land distribution and the main production strategies adopted in the rural settlements of the southern half of the Rio Grande do Sul State (RS, Brazil) in recent years, considering the environmental compatibility with the size of the lots. Questionnaires and semi-structured interviews were conducted with qualified agents related to the agrarian region, as well as analysis of documents and bibliographies. The region studied had in their formation process of environmental transformation that constituted the Pampa biome, which is the result of coevolution between humans and biota, since the occupation of the territory by people from Tradition Umbu, who introduced fire management for hunting. With the arrival of Europeans and extensive livestock, the system was transformed through a process of environmental adaptation, resulting in the current form of the biome, with fields of high biodiversity. During the twentieth century this system was strongly influenced by the set of strategies and techniques related to agricultural production and agribusiness expansion in the region, that caused significant losses of biome biodiversity. In the 1980s, from social pressures for land reform in the region, emerged settlement policies with perspective of a strategy to encourage the development of the southern half of the RS. In these allotments, lands were divided into rural modules ranging from 10 to 30 hectares. The results demonstrate that the method used in the distribution, combined with conventional agricultural practices, will not guarantee environmental preservation of biome and will not make possible the reproduction of socioeconomic families in the medium and long term. From this analysis, it is evident that lots distributed, conditioned on socioeconomic and cultural fabric existing in the region, will lead to further loss of biodiversity and social inequalities. This process can only be reversed with consistent distribution methods and practice of compatible agriculture, on the basis of sustainable rural development.

Keywords: Sustainable rural development. Land reform. Public policies.

\section{INTRODUÇÃO}

Redes (St. Cruz Sul, Online), v. 20, n² 2, p. 213 - 235, maio/ago. 2015214 
Neste artigo, analisam-se as transformações ocorridas no meio rural da Metade Sul' (MS) do Rio Grande do Sul (RS) nas últimas décadas. A partir dos anos 80 do século XX, houve mudanças efetivas da distribuição fundiária, que provocaram alteração no cenário socioeconômico e ambiental da região.

Por meio de uma análise histórica, percebe-se que a ocupação humana na região esteve vinculada à exploração pecuária. Essa prática entrou em estagnação econômica a partir da segunda metade do século XX. A partir desta época, a região passou por fortes transformações no uso da terra, por meio de um modelo de produção que, ao mesmo tempo, trouxe ganhos econômicos para os grandes proprietários rurais, seguindo a lógica do mercado exportador de grãos, mas manteve as desigualdades sociais, acarretando, ainda, perdas na biodiversidade e na cobertura vegetal características do bioma Pampa. A expansão de monoculturas agrícolas e a inserção de monoculturas florestais, já nos últimos anos desse século, aprofundaram esse processo.

Os assentamentos da reforma agrária foram criados na região a partir da década de 1980, em um contexto que tinha a prerrogativa de provocar uma transformação dessa realidade histórica, por trazer novas perspectivas em suas políticas: justiça social, desenvolvimento sustentável da agricultura familiar, soberania e segurança alimentar, em especial. Analisar se o método de distribuição de terras e a trama socioeconômica e cultural do contexto regional viabilizaram essas perspectivas, é o que propõe este trabalho. Utilizou-se de questionários e entrevistas semiestruturadas realizadas com agentes qualificados, além da análise de documentos e bibliografias.

Este texto está dividido em nove tópicos, além desta introdução e das considerações finais: nos três primeiros, faz-se uma análise da formação do Bioma Pampa e do desenvolvimento socioeconômico da MS, no $4^{\circ}$ e no $5^{\circ}$ tópicos, analisa-se o contexto da reforma agrária na região. Nos tópicos $6,7,8$ e 9 , é feita uma análise das principais

\footnotetext{
1 No contexto deste trabalho iremos considerar o termo Metade Sul (MS) como sendo a região que abrange a fronteira-oeste, a região sul e a parte central do estado do Rio Grande do Sul. Esta definição será usada como uma configuração socioeconômica e geopolítica. Já o termo bioma Pampa, que se refere ao ecossistema que compõe esta região, será utilizado ao referir-se aos aspectos físicos e ecológicos deste mesmo espaço.
} 
estratégias produtivas adotadas pelos assentados, caracterizadas como: agroecologia, agricultura monocultora e pecuária familiar, considerando suas possibilidades e limitações para um desenvolvimento rural sustentável. Por fim, nas considerações finais, a partir do contexto empírico estudado, sintetizam-se as perspectivas de sustentabilidade da reforma agrária na região.

\section{FORMAÇÃO DO BIOMA PAMPA}

O Bioma Pampa é o ecossistema que constitui a paisagem que se estende da MS do RS até o Uruguai e norte da Argentina. Tem como características peculiares a paisagem aberta e a vegetação campestre. Essas vastas extensões de campos que dominam a paisagem riograndense contêm traços da história da ocupação humana e das diferentes formas de manejo que proporcionaram diversas formas de respostas adaptativas do ambiente, resultando em níveis diferenciados de estabilidade. Com as mudanças na forma dominante de manejo, devido aos diferentes ciclos culturais da ocupação humana, sucederamse diversas combinações de regimes de perturbação dos ecossistemas, que levaram a biota e a cultura a processos adaptativos, com níveis de estabilidade atingidos em escalas temporais variadas, uma vez que a velocidade das mudanças culturais e, portanto, do manejo, foram aceleradas a partir da chegada do europeu. Essa dinâmica foi mais fortemente alterada a partir da última metade do século XX (CRUZ; GUADAGNIN, 2010).

Pode-se afirmar, a partir da sistematização da história ambiental do bioma, abordada por Cruz e Guadagnin (2010), que houve uma coevolução entre seres humanos e a biodiversidade local, resultando em adaptações mútuas condicionadas pelo manejo proporcionado pela ocupação humana, caracterizando transformações socioambientais adaptativas entre as espécies.

Passado um período de mais de sete mil anos após a extinção da megafauna da região, ocasionada pelos primeiros humanos ocupantes, os padres missioneiros jesuítas trouxeram novos grandes herbívoros para o Bioma Pampa, onde se destacam os bovinos e equinos. As primeiras notícias das Missões em território rio-grandense datam de 
1605 e, a partir de 1626, as Missões Jesuíticas espanholas se estabeleceram e fundaram as chamadas reduções (ROCHA, 2011 , p. 48).

A ocupação da região pelas missões jesuíticas se deu num período de vários conflitos entre as coroas portuguesa e espanhola, que ocuparam boa parte do século XVII. O principal legado dos padres missioneiros foi a inserção de grandes herbívoros exóticos no RS. Ao abandonarem o território, forçados por conflitos entre as duas coroas, deixaram uma considerável quantidade de rebanho, que, com o passar dos anos, multiplicou-se livremente, formando imensas reservas de gado bem adaptado ao ambiente (ROCHA, 2011 , p. 52).

Isso deu início a uma nova fase de transformações ambientais ao mudar novamente o manejo sobre os ecossistemas, com um diferente regime de perturbações na retomada da pressão pelo pastoreio e pisoteio de grandes mamíferos (que tinham sido extintos cerca de 7.600 anos antes), por meio de um rebanho que teve grande expansão em curto período de tempo (CRUZ; GUADAGNIN, 2010). De acordo com os mesmos autores, a partir de 1870 , com o cercamento das propriedades, impôs-se um manejo de lotação nas estâncias que levou a uma seleção natural com base no pastoreio, pisoteio e no fogo, resultando em uma sucessão vegetal com resgate do banco de espécies adaptadas ao pisoteio que sobreviveram em relitos ou em baixa densidade. Esse processo resultou em campos de alta diversidade, com cerca de 400 espécies de gramíneas, 150 de leguminosas e cerca de 3.000 espécies no total do bioma resultante.

\section{A FORMAÇÃO ECONÔMICA DA METADE SUL DO RIO GRANDE DO SUL}

Conforme Rocha (2011), a ocupação espacial portuguesa da MS se deu com interesse político-militar em meados do séc. XVIII, organizada pela Coroa Portuguesa que distribuiu grandes lotes de terra, as denominadas sesmarias, com a finalidade de garantir o domínio político do vasto território no sul da América.

Os "estancieiros", assim chamados os primeiros ocupantes das terras do sul do RS, na sua maior parte ex-militares aproveitados pela Coroa Portuguesa para ocuparem o território, estabeleceram a pecuária 
extensiva como principal atividade agropecuária, possibilitada pela ampla multiplicação do gado abandonado pelas Reduções Jesuíticas.

A diversificação da matriz produtiva não foi uma necessidade dos estancieiros da região. Para Rocha (2011), a baixa demanda por mão de obra e a facilidade para incorporar novas terras favoreceram, principalmente, atividades vinculadas à criação de bovinos e ovinos como a melhor opção de reprodução socioeconômica.

A economia da MS encontrou, no inicio do século XIX, com a implantação em território rio-grandense da indústria de salgamento da carne, as denominadas charqueadas, um canal de escoamento para seus rebanhos que, até então, só eram comercializados para a retirada do couro, para o transporte de cargas, e para alimentação na região das minas de ouro na região central do Brasil (ROCHA, 2011).

Porém, mesmo com o incremento do comércio de gado ocasionado pela indústria do charque, não houve alteração nas formas de produção dos rebanhos. A exclusividade na atividade pecuária foi uma característica na formação econômica do RS desde a sua origem em meados do século XVIII. Essa atividade originou-se da vinda dos primeiros povoadores, seja pelo caráter religioso dos jesuítas, seja pela estratégia militar de ocupação de espaços da coroa portuguesa.

Percebe-se que o comportamento conservador dos estancieiros sul rio-grandenses, nessa época, no que se refere à forma de administrar seu patrimônio, não era decorrente, obrigatoriamente, de sua ignorância ou incompetência como agentes econômicos, como algumas análises históricas concluem, mas, sim, de uma racionalidade específica, baseada nas características geográficas da região e da formação cultural originária ainda das estratégias de ocupação territorial da coroa portuguesa (ROCHA, 2011 ).

Os estancieiros mantiveram-se em uma mesma atividade produtiva, pelo absoluto desconhecimento de outras formas de produzir, mesmo quando, a partir do final do século XIX, a economia pecuária já se mostrasse em declínio.

Com isso, nota-se que a MS do RS caracterizou-se pela predominância das atividades pecuárias. Ainda em 1940, por exemplo, estas atividades representavam $65,85 \%$ do valor bruto da produção agrícola (BANDEIRA, 1994). 
$\mathrm{Na}$ forma em que essa relação entre seres humanos e ambiente influenciou as relações socioeconômicas, estabeleceram-se, também, as bases culturais da tradição gaúcha no RS, na medida em que a sociedade local se relacionava com o meio, elucidando a coevolução entre transformações ambientais e sociedade, o que constituiu o Bioma Pampa (CRUZ; GUADAGNIN, 2010).

\section{QUESTÃO AGRÁRIA NA REGIÃO: TRANSFORMAÇÕES DA TRAJETÓRIA CAPITALISTA}

Com o declínio na comercialização do charque e as limitações na adaptação ao mercado de carnes frigorificadas, já na segunda década do século $\mathrm{XX}$, intensificou-se a estagnação econômica na $M S$, oriunda da crise do modelo de produção pecuária (ROCHA, 2011); (PICCIN, 2012). $\mathrm{Na}$ metade do século $X X$, começa uma nova fase de transformações ambientais no bioma, constituído pelo avanço da agricultura industrial, que iria causar fortes transformações aos ecossistemas da região, descaracterizando o "sistema campo" (CRUZ; GUADAGNIN, 2010).

Isso se deve a formas produtivas ambientalmente insustentáveis implantadas na região especialmente após a Segunda Guerra Mundial, quando os princípios da Revolução Verde e a exigência mercantil por altos índices de produtividade tanto na pecuária como, principalmente, na produção de grãos (commodities agrícolas), levaram a densidades de lotação e áreas cultivadas superiores à capacidade de suporte do bioma.

As atividades relacionadas à agricultura monocultora ganharam maiores proporções na MS a partir da segunda metade do século XX. A rizicultura foi o principal cultivo em larga escala desenvolvido pela lógica mercantil, e no início do século XXI continua sendo um dos setores mais capitalizados do Estado.

A superfície cultivada com arroz irrigado no RS já na safra de $1921 / 1922$, era de 79.120 ha. No período entre 1921 a 1990, ao longo de 69 anos, houve um incremento de 712.130 ha cultivados. No período mais recente, entre 1990 a 2011 , ao longo de 21 anos, houve um incremento de 379.288 ha cultivados, alcançando a marca de 1.170.538 ha cultivados na safra 2010/11 (IRGA, 2011). 
Outras atividades agrícolas de cunho mercantil são desenvolvidas no RS em sua área agrícola de mais de 20 milhões de ha, ocupando posições de destaque também na MS, sobretudo na produção de soja, também de milho e trigo. No estado, o cultivo de soja ocupa 4.021.778 ha, o de milho 1.151.397 ha e o de trigo 2.182.667 ha (IBGE, 2012).

Um dos novos fatores da expansão agrícola no RS foi o aumento da área de cultivo de soja no Bioma Pampa, no final do século XX e nas primeiras décadas dos anos 2000. Esse processo denominado de "despecuarização" da MS se deve aos preços mais acessíveis de terras da região em relação às terras do planalto rio-grandense, tradicionalmente ocupado e já praticamente saturado pela produção de soja.

Políticas silvícolas também estão contribuindo para mudanças ambientais e socioeconômicas na MS. Essas políticas incentivam o plantio de árvores exóticas, especialmente os eucaliptos, e passaram a ser encaradas nas últimas décadas como um fator economicamente viável por muitos agentes de desenvolvimento do estado. A principal justificativa é a necessidade imediata de investimentos na MS. Este processo foi claramente uma alternativa condicionada a pressões de grandes empresas de capital estrangeiro, que perceberam variáveis mercantis favoráveis à expansão de seus negócios na região, em especial o preço das terras agrícolas, a mão de obra disponível e barata e o incentivo de infraestrutura (melhorias em estradas viárias, por exemplo), que alguns municípios lhes ofereceram.

Um desses programas para desenvolvimento florestal no RS é o Pró-Flora, que identifica um milhão de ha no estado como meta inicial para a expansão silvicultural (CRAWSHAW et. al., 2007). Entre 2002 e 2008, a área de silvicultura aumentou em 30\% no RS, a maior parte sobre campos (BENCKE, 2009). Como consequência disso, nas últimas décadas do século $X X$, percebe-se uma forte expansão de atividades ligadas à agricultura industrial e ao plantio de árvores no RS.

Os principais impactos ambientais identificados para esses cultivos estão ligados à depreciação da paisagem natural, barreira à fauna, alteração dos ciclos hidrológicos (redução dos mananciais hídricos), destruição do banco de sementes de espécies vegetais nativas e endêmicas, alteração da microbiologia e comprometimento da biodiversidade como um todo (BRACK, 2007, apud IBGE, 2010). 
A partir de dados do IBGE, é possível identificar impactos iniciais da expansão das monoculturas em relação à cobertura de pastagens no RS. Num período de 36 anos, entre 1970 e 2006, ocorreu no RS supressão de áreas com pastagens naturais em $41 \%$ (IBGE, 2012). Nesse período, o rebanho bovino aumentou no RS e o rebanho ovino diminui. Entretanto, a pressão de pastejo do rebanho bovino é maior em relação ao ovino e, ao levar em conta que as áreas com pastagens naturais e cultivadas diminuíram em 37\% em 36 anos no RS (1970 a 2006), pressupõe-se uma maior pressão sobre os campos (IBGE, 2012).

Pode-se afirmar que os campos do RS estão condicionados a maiores densidades de pastoreio, de forma crescente em relação aos últimos 40 anos. Halford et al. (2008) analisaram uma mesma vegetação ao longo de 20 anos e confirmaram que a alta intensidade de pastejo, a longo prazo, modifica significativamente a composição da pastagem, formando áreas de sobrepastejo homogêneas caracterizadas por um conjunto específico de espécies (HALFORD et al., 2008 apud CARVALHO et al., 2009).2

No bioma Pampa ocorreram mudanças significativas nas últimas décadas do século XX e, até certo ponto, ainda pouco compreendidas, ao considerar as formas de manejo influenciadas pelas relações econômicas capitalistas na região, que seguiram as demandas internacionais. Para Cruz e Guadagnin (2010), esse processo envolveu uma fragmentação dos campos naturais do bioma Pampa e a substituição para uma matriz de agroecossistemas. Nos últimos 50 anos, estima-se que a substituição de ecossistemas de campo por agroecossistemas chegou em torno de $60 \%$ da área original. No inicio do século XXI, sobrou somente $40 \%$ da área original, sendo que, destas, somente $22 \%$ são campos nativos, $5 \%$ são florestas $13 \%$ mosaicos de campos e florestas. Somente em torno de $13 \%$ desses remanescentes encontram-se em bom estado de conservação.

Além disso, essas mudanças em torno de um modelo de desenvolvimento trouxeram, além de impactos ambientais, efeitos

\footnotetext{
2 Uma das espécies introduzidas na década de 1950 foi o capim-anonni (Eragostis plana), que tem mostrado grande potencial invasor sobre campos nativos pastejados (pelo menos 400.000 hectares invadidos), com perda de qualidade forrageira e de biodiversidade (OVERBECK et al., 2009).
} 
socioeconômicos que pouco modificaram a conjuntura socioeconômica da MS. Esta formada por uma elite rural monocultora (grandes proprietários rurais), que dominou a economia e a política da região por séculos e, de outro lado, uma classe social desprovida dos meios de produção com poucas perspectivas de trabalho (trabalhadores rurais), demonstrando uma forte concentração de riquezas nas mãos de poucos grupos sociais.

A crise econômica da região ficou mais evidente a partir do pós guerra e foi identificada por meio da participação da Região Sul no PIB do RS: em 1939 a região gerava $38,33 \%$ e passou a gerar apenas $17,20 \%$ em 2000, conforme Bandeira, 2003 apud Alonso, 2003, demonstrando um forte declínio, especialmente se comparado à expansão econômica da região norte do estado nesse mesmo período.

Nota-se que o foco da produção agropecuária na MS sempre foi voltado para o mercado externo de produtos primários. Esses produtos são geralmente oriundos de grandes propriedades concentradoras de bens e riquezas. A falta de indústrias e o baixo valor agregado à exportação da produção agropecuária tem influência sobre a diminuição da participação no PIB do RS e da distribuição desigual de renda na MS.

Alonso (2003) comenta que outros setores entraram em declínio ao serem atingidos negativamente pela crise. Em algumas cidades da Campanha e da Fronteira Oeste, a participação no produto industrial do estado foi reduzida de 12,81\%, em 1990, para 9,60\%, em 2001. O comércio teve reduzida sua participação no PIB comercial do estado de $18,62 \%$ para $15,07 \%$ no mesmo período.

\section{MUDANÇA DE PERSPECTIVA: CRIAÇÃO DE ASSENTAMENTOS RURAIS NA METADE SUL DO RIO GRANDE DO SUL}

$\mathrm{Na}$ estrutura fundiária resultante da trajetória de desenvolvimento da MS, a pequena agricultura familiar baseada na pequena propriedade de produção diversificada, característica da região norte e nordeste do RS, é praticamente ausente até os anos de 1980, quando começam os primeiros assentamentos rurais. Nessa época, também os movimentos sociais ligados à luta dos pequenos agricultores pelo direito à terra, em especial o Movimento dos Trabalhadores Rurais Sem Terra-MST, passaram a atuar mais efetivamente na região. 
Para as organizações ligadas à reforma agrária no país (MST, Instituto de Colonização e Reforma Agrária-INCRA, Ministério do Desenvolvimento Agrário-MDA, entre outras) a emergência de encontrar colocação para a população excedente da zona rural da região norte do estado, devido ao resultado da subordinação ao capital agroindustrial que gerou êxodo rural, aliada à estagnação econômica e formação latifundiária na MS, além das pressões exercidas pelos movimentos sociais para desapropriações na MS, foram fatores determinantes para as políticas de assentamentos implantadas nesta região a partir dos anos de 1980 (ALVES, et al., 2007).

Para Buth e Corrêa (2006), desde a década de 1980, os movimentos sociais ligados ao campo, especialmente o MST, começaram a direcionar suas ações na busca de uma reterritorialização na MS. A partir da redistribuição de terras em áreas de latifúndios improdutivos e áreas subutilizadas (propriedades rurais que não cumprem sua função social), configura-se uma nova política de desenvolvimento rural num redirecionamento das estratégias de desapropriação para reforma agrária no RS, da região norte para a MS do RS.

Atualmente, no RS, estão assentadas aproximadamente 13.000 famílias, dispostas em 330 projetos de assentamento (INCRA, 2011). Na MS, os agricultores assentados se apresentam como novos agentes sociais em uma região conhecida por sua estagnação socioeconômica e agricultura de monocultivos.

No RS, as unidades de tipo familiar representam $86 \%$ do número total e ocupam apenas $31 \%$ da área total, mas contribuem com $54 \%$ do Valor Bruto da Produção e participam com $81 \%$ da ocupação de mão de obra (FRANÇA et al., 2009).

Nesse contexto, a agricultura familiar apresenta as características peculiares para um desenvolvimento rural sustentável, pois vem demonstrando maior vitalidade e capacidade para alcançar melhores resultados socioeconômicos, dados os seguintes aspectos:

i) multifuncionalidade e policultivos; ii) eficiência produtiva e eficiência energética e/ou ecológica; iii) conservação dos recursos naturais não renováveis; iv) proteção da biodiversidade e sustentabilidade futura; v) manejo meticuloso e fino (especialmente dos solos); e vi) atividades artesanais de 
menor impacto ambiental e com maior relevância social (COSTABEBER; CAPORAL, 2003).

Entretanto, faz-se necessário analisar nos assentamentos da MS o método utilizado para distribuir as terras com o objetivo de entender sua compatibilidade social, ambiental e econômica. A expectativa é que a pequena agricultura familiar na região implemente processos produtivos de caráter compatível com as peculiaridades do bioma Pampa, com manejo meticuloso e a diversificação de culturas agrícolas, que, além de assegurar a reprodução socioeconômica, via mecanismos de mercado, também atente para a segurança alimentar das famílias assentadas.

Outro fator a ser considerado são as principais estratégias produtivas adotadas pelos assentados, que explicitem indícios de sua (in)compatibilidade com o tamanho dos lotes no contexto local, ambiental, socioeconômico e cultural da MS. É essa análise que os próximos tópicos irão abordar.

\section{DISTRIBUIÇÃO DE TERRAS PARA ASSENTAMENTOS RURAIS: A (IN)COMPATIBILIDADE DO TAMANHO DOS LOTES NO BIOMA PAMPA}

No Brasil, o Estatuto da Terra e as políticas de utilização fundiária do século XX têm origem em meio ao pensamento da economia neoclássica de conceitos tipicamente produtivistas. A Revolução Verde era difundida numa perspectiva de tornar os camponeses novos empresários agrícolas, a partir de sua inserção no mercado de insumos e agroindústrias (MELLO, 2007). Esse paradigma norteou parte considerável das políticas formuladas nesse período.

Por outro lado, também em meados do século XX, a legislação brasileira adota uma nova noção para a propriedade rural, com um forte conteúdo social, deixando para trás as tradicionais concepções de propriedade individualista. Na nova noção, o benefício individual toma um caráter social, é valorizado o ser humano e seu trabalho não só para a família, mas para toda a comunidade, onde a terra é encarada não só como um fator de produção, mas um lugar de viver (ARAUJO, 1997).

Nesse sentido, o conceito de função social da terra é responsável por estabelecer critérios que identifiquem a forma de utilização da terra para que seu uso pelo proprietário se reflita num benefício social. A 
função social é definida pelo artigo 186 da Constituição Federal (CF) de 1988:

A função social é cumprida quando a propriedade rural atende, simultaneamente, segundo critérios e graus de exigência estabelecidos em lei, aos seguintes requisitos:

I- aproveitamento racional e adequado;

II- utilização adequada dos recursos naturais disponíveis e preservação do meio ambiente;

III- observância das disposições que regulam as relações de trabalho;

IV- exploração que favoreça o bem-estar dos proprietários e dos trabalhadores.

No Artigo 184 da CF, afirma-se que é dever do Estado desapropriar as propriedades que não cumprem sua função social, o que dá origem a destinação de terras para reforma agrária. A desapropriação é definida, então, como uma possibilidade de intervenção pública para que o uso da terra cumpra a função social.

Nota-se que, apesar de a função social compreender mais de um aspecto, sendo esses ligados a produtividade, relações de trabalho, bem-estar e meio ambiente, o Artigo 185 da CF coloca a salvo de desapropriação para fins de reforma agrária a propriedade produtiva. Conforme Araujo (1997, p. 97), essa medida "admite um só nível de garantia da propriedade, aquela que efetivamente produz ou que demonstre ser uma unidade econômica de produção." O autor afirma, ainda, que "o simples fato de ser produtiva não exclui os outros elementos caracterizadores de sua função social, apenas reforça-a".

Admite-se, portanto, de forma contraditória na legislação que o critério para desapropriação de terras por não cumprimento da função social é sua produtividade. Perde-se, assim, grande parte da noção social presente na legislação, pois, para cumprir com a função social, a própria legislação afirma que aspectos sociais e ambientais também são relevantes tanto quanto sua produtividade. 
Para dispor sobre a regulamentação dos dispositivos constitucionais relativos à desapropriação de propriedades improdutivas para reforma agrária, foi sancionada a Lei $n^{\circ} 8.629 / 93$, que determina, entre outros temas, os níveis de exploração econômica e racional mínimos para cumprir a função social e não caracterizar improdutividade. A produtividade do imóvel rural é avaliada no Art. 6 a partir do Grau de Utilização da Terra - GUT (rendimentos mínimos) e o Grau de Eficiência na Exploração - GEE (rendimentos). O artigo orienta a regulamentação de índices de rendimento para produção vegetal e índices de lotação para pecuária em todo Brasil.

Os índices de produtividade tem uma abordagem homogênea sobre os ecossistemas e, por isso, não levam em conta as peculiaridades e limitações ambientais de caráter local. São índices que incentivam o aumento de rebanhos ao ponto de gerar sobrepastoreio em áreas de alta fragilidade no bioma Pampa, que não tem tais capacidades de carga. É necessário não só revisar esses níveis, como também propor mudanças nas políticas públicas, para evitar que o manejo das propriedades cause fortes impactos, baseado somente na produtividade como forma de benefício social. Apenas o aspecto da produtividade não pode ser considerado como cumpridor da função social, pois índices intensivos de produção, muitas vezes, caracterizam impactos ambientais e degradação do capital natural, que é social e não individual.

A distribuição de terras para criação de assentamentos rurais é realizada pelo conceito de propriedade familiar, que se concretiza na definição de módulos rurais. Esse tipo de módulo segue alguns princípios para definir o espaço mínimo de um lote. No Estatuto da Terra de 1964, consta que as terras para fins de reforma agrária poderão ser distribuídas apenas sob a forma de propriedade familiar. Esse tipo de propriedade é definido nesta mesma lei, no artigo $4^{\circ}$, Inciso II, como:

o imóvel rural que, direta e pessoalmente explorado pelo agricultor e sua família, Ihes absorva toda a força de trabalho, garantindo-lhes a subsistência e o progresso social e econômico, com área máxima fixada para cada região e tipo de exploração, e eventualmente trabalhado com a ajuda de terceiros. 
O Módulo Rural é a área fixada nos termos da propriedade familiar. Essa unidade de medida leva em consideração ainda os critérios determinados pelo artigo 11 do Decreto $n^{0} 55.891$, de 31 de março de 1965:

Art. 11. O módulo rural, definido no inciso III do artigo $4^{\circ}$ do Estatuto da Terra, tem como finalidade primordial estabelecer uma unidade de medida que exprima a interdependência entre a dimensão, a situação geográfica dos imóveis rurais e a forma e condições do seu aproveitamento econômico.

Parágrafo único. A fixação do dimensionamento econômico do imóvel que, para cada zona de características ecológicas e econômicas homogêneas e para os diversos tipos de exploração, representará o módulo, será feita em função:

a) da localização e dos meios de acesso do imóvel em relação aos grandes mercados;

b) das características ecológicas das áreas em que se situam;

c) dos tipos de exploração predominantes na respectiva zona.

Nesses critérios, a legislação admite os fatores geográficos e o aproveitamento econômico de forma coerente com o tamanho do imóvel, respeitando, ainda, fatores ambientais, comerciais e regionais. Apesar desse discurso, para operacionalizar essa lei foram criadas tabelas fixando tamanhos de módulos de acordo com tipos de exploração: hortigranjeiro, de cultura permanente, de cultura temporária, de exploração pecuária, de exploração florestal ou de exploração indefinida. Essa tabela é aplicada a todos os municípios do país, sendo que, por meio dela, boa parte dos biomas e ecossistemas é mais uma vez homogeneizada em sua capacidade de ocupação, índice de produtividade e consequente fragilidade ambiental. 
Os valores definidos na década de 1980 estão, ainda, sem as atualizações previstas em lei para que se tenha maior compatibilidade local. Na medida em que os estudos sobre os biomas avançam, principalmente no bioma Pampa, surgem novas evidências que poderiam redefinir as estratégias para definição de módulos rurais na criação de assentamentos.

$\mathrm{Na}$ discussão em torno da definição do tamanho dos lotes de assentamentos no RS, o estudo de Mello (2007) contribui para expressar a visão do INCRA e suas considerações para tomada de decisão na distribuição de terras. $O$ trabalho teve como objetivo analisar o tamanho de módulo viável economicamente, a partir de assentamentos existentes no RS, considerando os sistemas de produção dos assentamentos e suas rentabilidades para gerar uma renda mínima (um salário mínimo mensal) para cada Unidade de Trabalho Humano-UTH³. A média de UTH nos assentamentos do RS é de 1,94 por família, conforme o autor. Próximo desse valor, o nível de renda esperado pelo programa de consolidação dos assentamentos é que atinjam uma renda média mensal de dois salários mínimos/família para serem considerados emancipados (MELLO, 2007).

Os sistemas de produção analisados são resultado de levantamentos nos assentamentos existentes e expressam um modelo de produção intensivo, na produção de agricultura anual com monoculturas e agropecuária (MELLO, 2007), uma estratégia que pode ser considerada necessária sob o ponto de vista econômico para manutenção das famílias em pequenas propriedades. Nesse sentido, um dos pressupostos para a definição dos lotes neste estudo é que:

o módulo deve garantir a sobrevivência da família assentada numa situação produtiva difícil. A partir daí, pode-se, em tese, intensificar a produção e adotar sistemas mais rentáveis e mais diversos (MELLO, 2007).

\footnotetext{
3 Unidade de Trabalho Humano (UTH): equivalente à força de trabalho de um trabalhador adulto (17 aos 59 anos) em 287 jornadas/ano.
} 
Com o estudo acima referido, uma das conclusões obtidas é respaldar uma tendência à diminuição dos lotes de reforma agrária (MELLO, 2007) a partir de práticas intensivas e rentáveis de produção em todo o estado. Essa tendência se deve tanto pela crescente quantidade de famílias acampadas que lutam pela terra quanto por dificuldades em desapropriar por função social, assim como pelo crescente preço das terras no RS e a reduzida quantidade de recursos destinados pelo governo federal ao INCRA (INCRA, 2013, p. 219; COLUSSI, 2013).

O estudo aponta como viáveis economicamente módulos de 9 a 30 ha, dependendo da região e do sistema de produção adotado, a partir de diagnóstico dos assentamentos existentes, considerando os sistemas: grãos (milho, arroz, soja, trigo), leite, carne, fumo, e para todos sistemas a produção de mamoma (entre 10 e $20 \%$ da renda total do lote) (MELLO, 2007). Nota-se que a produção de mamona ainda não é uma estratégia produtiva viável com meios de produção consolidados no RS e foi calculada como fonte de renda importante nos assentamentos.

Por considerar apenas os sistemas de produção nos lotes dos assentamentos existentes que vivem em condições socioeconômicas limitantes e são condicionados à exploração intensiva da propriedade para manutenção da família, o estudo citado não considerou um modelo tradicional de pecuária familiar (ocupa maiores áreas de terra), por necessidade de justificar uma tendência para menores lotes. Deve-se atentar para essa intensificação dos sistemas, pois ela depende do tipo de manejo e técnicas adotadas, podendo levar a um aumento de renda, mas também, a uma maior degradação do capital natural.

Um fator recente que influi sobre o tamanho dos módulos é o conteúdo da Portaria $n^{\circ} 7$ do MDA de 31 de janeiro de 2013, que estabelece valor máximo para obtenção de imóvel por família beneficiada, e considera como variáveis a região geográfica e bioma incidente. No bioma Pampa, o valor do imóvel será de no máximo R\$ $90.000,00$ (noventa mil reais) e levará em conta os preços do mercado de terras.

Conforme pesquisa da Informa Economics FNP, divulgada por Colussi (2013) no Jornal Zero Hora, os preços por ha na região norte do 
estado, maior produtora de grãos do RS, podem passar de $\mathrm{R} \$ 40.000,00$ reais. $\mathrm{O}$ alto valor dessas terras e as últimas safras exitosas incentivam investimentos que se voltam para regiões, até então, pouco exploradas para plantio de soja. As terras que passam a ser incorporadas por esses produtores são as da MS, que estariam avaliadas em $\mathrm{R} \$ 10.000,00$ por ha nas áreas de potencial produtivo. Conforme o estudo o aumento de preços nas regiões de São Borja e São Gabriel, alcança o valor de $600 \%$ por ha nos últimos dez anos.

Com essa valorização das terras na região e a portaria do MDA que define um valor máximo na obtenção de imóvel por família, estabelece-se uma forte limitação no tamanho das terras que serão distribuídas para os próximos assentados, onde continua a tendência de diminuição dos lotes de reforma agrária, e se agrava o risco de insustentabilidade desse modelo.

Esse modelo de desapropriação e distribuição de terras aqui exposto pode contribuir com o processo de substituição de ecossistemas de campo por agroecossistemas que, desde meados do séc. XX, ocasiona forte perturbação dos campos do Bioma Pampa.

Tomando as referências da legislação agrária brasileira aqui analisada, pode-se considerar que as consequências das políticas de reforma agrária atuais em relação aos produtores rurais que se sentem ameaçados pela desapropriação de suas terras, é o aumento das lotações de rebanho e a mudança de sistemas produtivos da pecuária para agricultura industrial. $O$ objetivo é atingir os níveis de produtividade exigidos por lei, já que esta é a única exigência percebida pela legislação.

Para os agricultores que lutam pela reforma agrária, viabiliza-se a criação de assentamentos rurais e o acesso à terra. Entretanto, isso se dá em pequenos módulos rurais condicionados a um manejo intensivo e, muitas vezes, com monocultivos e agricultura industrial. Essa estratégia torna-se incompatível do ponto de vista da sustentabilidade socioambiental, pois não tem sustentação em longo prazo.

\section{ESTRATÉGIAS PRODUTIVAS NOS ASSENTAMENTOS}

Nesse tópico, serão analisadas três das principais estratégias produtivas que atualmente são implantadas pelos agricultores 
assentados na MS, uma delas ligada a uma lógica mercantil de viabilidade, porém contestável sob a perspectiva da sustentabilidade para projetos de assentamentos (monocultura da soja). A outra é característica da formação do bioma Pampa, mas que apresenta dificuldades de implantação no contexto dos pequenos lotes, e foi parcialmente adaptada para essa condição (pecuária familiar). Uma terceira estratégia está ligada à agroecologia e tem perspectivas de sustentabilidade mais compatível em longo prazo (arroz agroecológico), mas ainda carece de certas condições para uma maior efetividade, desde avanços tecnológicos, como, também, de políticas públicas e incentivos com pesquisa e extensão.

\section{AGRICULTURA MONOCULTORA DA SOJA}

Os levantamentos realizados por esta pesquisa constataram que a agricultura monocultora de produção de soja é tomada como opção imediata de obtenção de renda pelos assentados logo nos primeiros anos do assentamento, muitas vezes, sem a devida avaliação de seus riscos. Essa prática é comum tanto para aqueles agricultores oriundos da região norte do estado, onde esses métodos foram amplamente difundidos para pequenos, médios e grandes produtores desde a década de 1970, quanto por aqueles oriundos da própria MS, que se sentem motivados a adotarem estratégias produtivas de aparente viabilidade econômica e social. Com isso, essa monocultura está em expansão, possuindo meios de comercialização consolidados e possibilidade de lucros econômicos imediatos, mediante consideráveis investimentos.

Essa prática entre os agricultores assentados é resultado, também, de uma forte pressão do entorno cultural, numa trama socioeconômica que influencia a tomada de decisão por esse tipo de cultivo.

No Brasil, a produção de soja tende a se expandir e se concentrar na região centro-oeste em grandes propriedades. Esse é um dos motivos pelos quais esse cultivo não representa uma alternativa viável aos pequenos agricultores na MS, pois, ao exigir altos investimentos e crescentes áreas de terra para expansão, colocará em risco a reprodução socioeconômica dos pequenos agricultores familiares 
assentados em pequenas propriedades que não atingem altas escalas de lucro para compensar os investimentos financeiros necessários. $\mathrm{Na}$ década de 1970, por exemplo, na região do planalto rio-grandense, a especialização dos agricultores na produção de soja e trigo, aliada a subordinação ao capital agroindustrial, via capital financeiro, resultou num processo de diferenciação social que induziu uma grande quantidade deles a abandonarem a agricultura (FRANTZ, 1982:129 apud ANDREATTA et al., 2009).

Considera-se que, para uma agricultura sustentável na MS, não se deve repetir o mesmo sistema produtivo da agricultura industrial que levou ao êxodo rural em décadas anteriores. Nesse caso, os agricultores assentados, ao cultivarem soja aos moldes do agronegócio, perdem a autonomia na produção, dependem de processos industrializados, ficam expostos aos agroquímicos e passam a ter suas colheitas subjugadas à lógica do capital mercantil. Além disso, na medida em que ocorre a especialização na produção para atingir maiores lucros de escala, é posta em risco a segurança alimentar das famílias assentadas.

Sob o aspecto ambiental são, também, inúmeros os impactos reais e potencias do cultivo de soja no bioma Pampa. O impacto inicial é a perda de cobertura vegetal e potencial utilização da biodiversidade local na substituição do campo nativo por cultivos agrícolas intensivos. Deve-se considerar que uma considerável parte dos solos da MS são altamente suscetíveis à erosão. Na remoção de cobertura vegetal e inserção da agricultura mecanizada, potencializam-se processos erosivos. A utilização de agrotóxicos é outro impacto evidente das monoculturas. A soja transgênica tem causado externalidades negativas em assentamentos entrevistados, onde as lagartas migraram para outras plantações de vizinhos nas proximidades, inviabilizando produções orgânicas.

A deficiência hídrica na MS é uma limitação climática à produção em monocultivos. Conforme Matzenauer et al. (2002), na maior parte dos anos, a frequência e a intensidade das chuvas no período do desenvolvimento da soja, que ocorre entre novembro e março no RS, são insuficientes para que a cultura manifeste seu potencial produtivo (apud MELO et al., 2004). Por esse motivo, o clima é o principal fator responsável pelas oscilações de produtividade e frustrações da cultura da soja no estado conforme Melo et al. (2004). Estima-se que 93\% das 
perdas na safra de soja ocorram em razão das estiagens (BERLATO; FONTANA, 2003 apud MELO et al., 2004).

\section{A PECUÁRIA FAMILIAR}

Na MS do RS, a pecuária familiar é uma atividade tradicional que envolve cerca de 50.000 famílias. Elas vivem no campo e têm a criação de bovinos de corte/ovinos como sua principal fonte de renda ou ocupando a maior parte do seu estabelecimento rural, sendo que realizam também alguns cultivos de subsistência (EMATER/RS, 2009). Esse modelo de exploração é mantido pelos pecuaristas familiares em propriedades de até 300 ha, consideradas pequenas, pois a renda monetária familiar com a atividade principal, muitas vezes, não ultrapassa dez mil reais anuais (FOCHEZATTO, 2004).

A lógica produtiva utilizada a partir de uma pecuária de baixa lotação e alta produtividade de carne também torna o tamanho da propriedade um fator determinante para a sustentabilidade. Conforme já discutido neste artigo, houve um processo de coevolução entre o manejo da pecuária e a adaptação ambiental, que, em níveis de lotação adequados, proporcionou a manutenção da biodiversidade do Bioma Pampa. Esses produtores mantêm suas práticas de pecuária de baixa lotação sustentável por um período superior a 200 anos. Entretanto, Netto (2009) afirma que a pecuária estaria fadada a desaparecer se depender de uma análise puramente econômica sobre seu desempenho, principalmente se comparada a outras alternativas de utilização da terra.

Nabinger et al. (2009) propõem formas de manejo para utilizar o potencial produtivo animal com base no campo nativo no bioma Pampa. A premissa básica é que o manejador deve ajustar a carga animal em função da disponibilidade de pasto. Isso significa controlar o nível de oferta de forragem, ou seja, a quantidade de pasto que cada animal deve encontrar diariamente a sua disposição.

\footnotetext{
"Ainda que para que possamos aumentar a oferta de forragem por animal tenhamos que diminuir a lotação isto não significa que, ao termos menos animais na área, haja prejuízo no ganho por área" (NABINGER et al., 2009).
} 
Isso quer dizer que o grau de produtividade é obtido a partir da relação entre carga animal e disponibilidade de pasto no manejo adequado, e não simplesmente a partir de um alto grau de lotação, sem o adequado acesso a pasto.

Partindo dessa análise de produtividade animal em campos do bioma Pampa, o modelo de pecuária familiar tem fortes limitações para ser replicado em lotes com 10 a 30 ha nos assentamentos de reforma agrária no bioma Pampa. Esses lotes não viabilizam rebanhos do ponto de vista econômico e ambiental devido à incapacidade de suporte das pastagens em pequenas propriedades, sendo que os ganhos econômicos e produtivos na pecuária dependem de sua conservação e disponibilidade. Considera-se que boa parte dos assentados de origem cultural pecuarista tem o saber para praticar esse tipo de exploração, a mais adaptada aos fatores ambientais locais, pois a manutenção do Bioma Pampa com pecuária representa a melhor opção de uso sustentável para fins de produção de alimentos (NABINGER et al., 2009). Porém, as limitações pelo tamanho da propriedade inviabilizam a prática de uma pecuária familiar de corte como principal renda econômica de uma família.

Nesse sentido, a principal estratégia adotada, relativa à prática da pecuária nos assentamentos, está ligada à produção de leite. Diferente da produção da carne, que tem comercialização geralmente sazonal ou por necessidades econômicas, o leite é vendido mensalmente e garante renda bem distribuída ao longo do ano para as famílias.

No caso dos assentamentos no Município de Santana do Livramento, a Cooperativa Regional dos Assentados da Fronteira Oeste Ltda.-Coperforte se fortaleceu a partir da integração dos assentados na produção e comercialização do produto (ROCHA et al., 2012). Entretanto, ainda não foram tomadas estratégias de maior agregação de valor do leite nessa cooperativa.

Outra experiência cooperativada é a dos assentados do Município de Pedras Altas, que demonstra uma estratégia diferenciada de agregação de valor na produção de leite, por meio da produção de queijos finos com resultados promissores.

Esses tipos de estratégia, no conjunto dos assentamentos da região, ainda é pouco significativo, mas abre possibilidade de se constituírem em alternativas compatíveis com a sustentabilidade das 
famílias assentadas na região (ROCHA et al., 2012). Considera-se essa uma estratégia onde a carga animal é mais adequada ao tamanho dos lotes, para uma produção coerente com as limitações ambientais e com a geração de renda e produção de alimentos.

\section{ARROZ AGROECOLÓGICO}

Esse tópico está baseado nas análises realizadas nos assentamentos localizados nos municípios de Santa Margarida do Sul e São Gabriel, de uma perspectiva socioambiental mais coerente com os princípios de uma sustentabilidade efetivamente compatível.

A produção de arroz orgânico teve início no RS a partir de meados dos anos 2000, por iniciativa das famílias assentadas, com o apoio de cooperativas ligadas aos movimentos sociais ao quais se vinculam, em especial do MST. Foram motivados pelo compromisso com a produção agroecológica e a perspectiva de conquistar um mercado diferenciado, uma vez que os agricultores assentados, que produziam arroz convencional, inviabilizavam-se economicamente devido à forte concorrência do arroz produzido pelo monocultivo latifundiário, dos baixos preços do arroz e dos altos custos de produção com o uso de agrotóxicos e outros insumos (CAMPOS; MEDEIROS, 2011).

Esse tipo de percepção e posicionamento para um redirecionamento estratégico vai ao encontro à análise de Schneider e Fialho (2000), no qual a redução da pobreza rural está associada à mudança da estrutura social e econômica que a produz. Para esses autores, é preciso considerar que não basta apenas possibilitar o acesso à terra, seguindo o mesmo sistema produtivo da agricultura convencional que levou ao êxodo rural em décadas anteriores. Deve-se promover uma mudança efetiva nas políticas públicas destinadas aos pequenos agricultores, em que as estratégias produtivas preconizem uma maior autonomia na produção e comercialização de produtos ambiental e socialmente compatíveis.

A produção do arroz, orientada pelos princípios agroecológicos, transforma radicalmente a produção das famílias envolvidas, que deixam de ser meras consumidoras de pacotes tecnológicos e se tornam responsáveis por gerar inovações. Atuando como observadoras, contribuem com as pesquisas sobre lavouras alternativas, 
propiciando uma reflexão sobre o desenvolvimento de uma nova relação entre produção agrícola e os biomas nos quais se inserem, promovendo transformações nessa cadeia produtiva, tanto na configuração territorial como na dinâmica social (CAMPOS; MEDEIROS, 2011).

A produção de arroz orgânico no Município de Santa Margarida do Sul se encontra em fase inicial, com duas colheitas até 2010. Kovalski (2010) analisou a produção de arroz ecológico de agricultor assentado do município durante o ano-safra 2009/2010 em um lote de 14 ha, que teve 12 ha destinados à lavoura orizícola e os outros dois restantes em policultivos destinados à subsistência. A base produtiva seguiu os preceitos da agricultura orgânica, sendo esta utilizada, também, em um processo pedagógico de aprendizagem, funcionando como lavouraescola para os demais assentados. A cultura escolhida pelo agricultor foi a IRGA 417, que se mostrou com boa produtividade e condições edafoclimáticas adequadas ao Bioma Pampa.

Mesmo com as muitas dificuldades inerentes à implantação, constatou-se que essa família assentada teve uma renda líquida de $\mathrm{R} \$$ $5.803,26$ na safra. Kovalski (2010) demonstra que a produção de arroz ecológico é economicamente viável como alternativa sustentável para ser desenvolvida no Bioma Pampa.

A estratégia agroecológica na produção de arroz aponta um caminho concreto para a promoção de uma tecnologia ecológica e adaptada à pequena produção.

Resta considerar que a produção de arroz na MS do RS deve ser relacionada com a conflituosa questão do consumo e disponibilidade de água nessa região. Apesar de ter se mostrado viável econômica e ambientalmente, salienta-se que, para expandir este tipo de cultivo na região, deve-se incentivar a pesquisa, na busca de estratégias que possibilitem uma orizicultura com o uso mais eficiente de água.

\section{CONSIDERAÇÕES FINAIS}

A partir do referencial apresentado, o estudo aponta como a relação entre ser humano e ambiente condicionou a permanência de uma estabilidade ambiental com alta biodiversidade na região do pampa gaúcho. A cultura gaúcha foi construída por essa relação entre origem cultural e manejo da pecuária de corte em campos abertos. Os 
pecuaristas familiares, que atualmente somam mais de 50 mil famílias, expressam como essa relação pôde se manter por mais de 200 anos, sustentando condições estáveis sob os pontos de vista ambiental e socioeconômico no bioma Pampa.

A ocupação territorial como estratégia político-militar da coroa portuguesa empregou um método de distribuição de terras de alta concentração fundiária. Essa estrutura social desigual se manteve por séculos até passar por sucessivas crises (ROCHA, 2011) e parcialmente mudar seu sistema produtivo. O manejo pecuarista familiar na MS, com relações socioambientais estáveis, passou a ser substituído, ainda em meados do século XX, por formas de produção capitalistas, ligadas à lógica do mercado internacional de exploração agrícola, o agronegócio. Essa transição foi responsável por reduzir a área da cobertura vegetal para $40 \%$ da original, com apenas $13 \%$ em bom estado de conservação (CRUZ; GUADAGNIN, 2010). A substituição do campo nativo por monoculturas já trouxe grandes perdas socioambientais no bioma Pampa, e tem o objetivo de se inserir, em sua maioria, em mercados internacionais, com produtos primários de baixa agregação de valor na região.

A reforma agrária como perspectiva de justiça social na distribuição de terras e de sustentabilidade ambiental num manejo coerente pela agricultura familiar, contrapondo as origens históricas de concentração fundiária e a transição mais recente para sistemas monocultores insustentáveis, é uma estratégia que foi implantada na forma de assentamentos para o desenvolvimento da região a partir da década de 1980.

Nas análises realizadas, percebeu-se que o tamanho dos lotes dos assentamentos criados ( 10 ha a 30 ha, em média) torna inviável a manutenção econômica, a sustentabilidade ambiental e a reprodução social dos agricultores assentados, quando estes praticam atividades agrícolas incompatíveis com os aspectos ecológicos do bioma Pampa. Ao utilizarem em seus lotes a produção de monoculturas (sobretudo soja), ou tentarem reproduzir a mesma lógica da produção de gado de baixa lotação dos pecuaristas tradicionais da região, os agricultores assentados reproduzem uma racionalidade pouco compatível com o tamanho do lote que lhes foi destinado. Portanto, inviabiliza-se tanto a manutenção ambiental como o sustento de sua família. 
Tanto a produção de soja quanto a pecuária de corte são condicionantes da trama socioeconômica e cultural que já existia na região, porém não devem ser replicadas nos pequenos módulos rurais, pois apresentam riscos ambientais, sociais e econômicos.

Já a produção agroecológica, nesse caso o arroz ecológico, poderá se constituir em uma das alternativas mais viáveis sob os três aspectos da sustentabilidade: ambiental, social e econômico. Contudo, para que essas estratégias alcancem seu potencial tanto de viabilidade como de ampla aceitação pelos agricultores familiares, são necessárias mudanças institucionais e políticas, com maiores investimentos públicos e prioridade nas estratégias agroecológicas; com melhoria na infraestrutura e oportunidade de acesso ao mercado de forma justa; mudança de atitude e filosofia entre cientistas, gestores e outros tomadores de decisão responsáveis por promover essas estratégias (ALTIERI, 2012). Tanto essas como outras necessidades para uma transição agroecológica são fatores imprescindíveis para viabilizar essa estratégia para reprodução socioeconômica das famílias e conservação do bioma.

Pode-se afirmar que a reforma agrária na região será viável a partir de estudos para reavaliação da compatibilidade dos módulos rurais em relação às peculiaridades socioambientais do Bioma Pampa, evitando avaliações homogêneas sob o ponto de vista ecossistêmico, como é o caso dos critérios que definem o tamanho dos módulos.

Percebe-se, também, que é necessária uma ampliação do sentido da "função social" da terra em sua aplicação legal no Brasil. Pelo Estatuto da Terra, ela é avaliada para desapropriação a partir de níveis de produtividade. A partir dos equívocos dessa lei, as evidências apontam para duas possibilidades no uso da terra na região: (1) os grandes produtores tendem a aumentar os índices de lotação ou mudam o sistema produtivo para um uso agrícola intensivo, e (2) os pequenos agricultores são assentados em pequenas propriedades. Ambas as possibilidades não são estratégias que manterão as condições ambientais nem trarão benefícios sociais, pois os pequenos produtores não se viabilizam social e economicamente, e os grandes produtores se utilizam de práticas intensivas e degradantes.

Nesse contexto, a valorização da força de trabalho na agricultura familiar deveria ser outro argumento importante na aplicação mais justa 
da função social da terra no Brasil. O resultado social do trabalho, onde o uso da terra pela pequena agricultura familiar gera benefícios sociais com distribuição de renda e produção de alimentos, é o maior fruto da Reforma Agrária, e tem relevância para ser considerado nos critérios de desapropriação de terras.

Apesar da incoerência constatada nessas políticas públicas, a reforma agrária no Bioma Pampa tem um potencial de unir os interesses produtivos com os interesses sociais e de preservação ambiental. Ao revisar os processos de formação desse Bioma, entende-se que sua conservação está ligada e depende do manejo eficiente da criação pecuária de baixa lotação, o que exigiria módulos rurais maiores.

Outro modo compatível é a produção baseada na transição para sistemas agrícolas sustentáveis na agroecologia. Esta deve ser mais incentivada por políticas públicas, principalmente nos assentamentos já criados, identificando-se as experiências exitosas já existentes. Essas perspectivas de produção, baseadas tanto em procedimentos construídos com características locais como com conhecimentos científicos ecológicos, propõem expectativas de produção compatíveis com a região, respeitando a heterogeneidade e biodiversidade do Bioma Pampa.

Propõe-se que as políticas de reforma agrária para essa região sejam repensadas tendo em vista as características e capacidades ambientais locais. A distribuição de terras deve tanto promover mudanças efetivas na estrutura fundiária como, também, garantir, em longo prazo, a manutenção das famílias assentadas nas bases de um desenvolvimento rural sustentável.

\section{REFERÊNCIAS}

ALONSO, J. A. F. O Cenário regional gaúcho nos anos 90: convergência ou mais desigualdade. Indicadores Econômicos FEE. Porto Alegre-RS, v. 31 , n. 3, p. $97-118,2003$.

ALTIERI, M. Agroecologia: bases científicas para uma agricultura sustentável. 3 ed. Rio de Janeiro-RJ: Expressão Popular, AS-PTA, 2012. 
ALVES, F. D.; SILVEIRA, V.C.P; FERREIRA, E. R. Territorialização camponesa, identidade e reproduções sociais: os assentamentos rurais na metade sul do Rio Grande do Sul. Campo-Território: Revista de Geografia Agrária. v. 2, n.4, p. 82-97, 2007.

ANDREATTA, T.; BEROLDT, L.; WANDSCHEER, E. A. R.; MIGUEL, L. A. Origens da formação agrária sul rio-grandense no contexto brasileiro. In: $47^{\circ}$ Congresso da Sociedade Brasileira de Economia e Sociologia Rural (SOBER), 2009, Porto Alegre-RS. Anais... Porto Alegre-RS: UFRGS, 2009.

ARAUJO, L. E. B. O acesso à terra no estado democrático de direito. 1997. 271 f. Tese (Doutorado em Direito) - Universidade Federal de Santa Catarina, Florianópolis. 1997. Disponível em: <http://www.egov.ufsc.br/portal/sites/default/files/anexos/1406814069-1-PB.pdf> Acesso em: 20 abr. 2013.

BANDEIRA, P. S. As raízes históricas do declínio da Região Sul. IN: ALONSO, J. A. F.; BENETTI, M. D.; BANDEIRA, P. S. (Org.) Crescimento econômico da Região Sul do Rio Grande do Sul: causas e perspectivas. Porto Alegre: Fundação de Economia e Estatística Siegfried Emanuel Heuser - FEE, 1994.

BENCKE, G. A. Diversidade e conservação da fauna dos Campos do Sul do Brasil. In: PILLAR, V. P. et al., (Org.) Campos Sulinos: Conservação e Uso Sustentável da Biodiversidade. Brasília: Ministério do Meio Ambiente, v.1, p. 101-121, 2009.

BRASIL. Decreto $n^{\circ} 55.891$ de 31 de Março de 1965. Diário Oficial da República Federativa do Brasil, 08 de abril de 1965. Disponível em: <http://www2.camara.leg.br/legin/fed/decret/1960-1969/decreto55891-31-marco-1965-396186-publicacaooriginal-43811-pe.html>. Acesso em: 12 mar. 2013.

BRASIL. Lei n. 4504, de 30 de novembro de 1964, Estatuto da Terra. Diário Oficial da República Federativa do Brasil, Brasília, DF, 30 de nov. de $1964 . \quad$ Disponível em: <http://www.planalto.gov.br/ccivil_03/leis/L4504compilada.htm>. Acesso em: 10 jun. 2012. 
BUTH, F.; CORRÊA, W. K. A reconstrução do território a partir de assentamentos rurais: o caso do assentamento Ramada - RS. CampoTerritório: Revista de Geografia Agrária, v. 1, n. 2, p. 152-172, 2006.

CAMPOS, S. S. C.; MEDEIROS, R. S. V. Análise territorial da cadeia produtiva do arroz ecológico nos assentamentos da região metropolitana de Porto Alegre - resultados preliminares. In: VI Encontro de Grupos de Pesquisa, 2011, Presidente Prudente. Anais... Presidente Prudente, SP: UNESP, 2011.

CARVALHO, P. C. F.; SANTOS, D. T.; GONÇALVES, E. N.; PINTO, C. E.; NEVES, F. P.; TRINDADE, J. K.; BREMM, C.; MEZZALIRA, J. C.; NABINGER, C.; JACQUES, A. V. A. Lotação Animal em Pastagens Naturais: políticas, pesquisas, preservação e produtividade. In: PILLAR, V. P. et al., (Org.) Campos Sulinos: Conservação e Uso Sustentável da Biodiversidade. Brasília: Ministério do Meio Ambiente, v.1, p. 215-228, 2009.

COSTABEBER, J. A.; CAPORAL, F. R. Possibilidades e alternativas do desenvolvimento rural sustentável. In: VELA, H. (Org.) Agricultura Familiar e Desenvolvimento Rural Sustentável no Mercosul. Santa MariaRS: Editora da UFSM/Pallotti, 2003.

CRAWSHAW, D.; DALLAGNOL, M.; CORDEIRO, J. L. P.; HASENACK, H. . Caracterização dos campos sul-rio-grandenses: uma perspectiva da Ecologia de Paisagem. Boletim Gaúcho de Geografia, v. 33, n. 1, p. 233252, dez. 2007.

CRUZ, R. C.; GUADAGNIN, D. L. Uma pequena história ambiental do Pampa: proposta de uma abordagem baseada na relação entre perturbação e mudança. In: COSTA, B. P.; DIECKEL, M. E. G. (Org.). $A$ sustentabilidade da Região da Campanha-RS: Práticas e teorias a respeito das relações entre ambiente, sociedade, cultura e políticas públicas. Santa Maria-RS: UFSM, PPG Geografia e Geociências, Dep. de Geociências, v. 1, p. 155-179, 2010.

EMATER/RS. Associação riograndense de empreendimentos, assistência técnica e extensão rural (EMATER/RS) - Associação sulina de crédito e assistência rural (ASCAR). Programa Estadual de Pecuária Familiar. Disponível em: <http://www.emater.tche.br/site/area/pecuaria.php>. Acesso em: 12 mar. 2013. 
FOCHEZATTO, A.; TRICHES, D.; HERRLEIN JR, R.; STÜLP, V. J. Apontamentos para o estudo da pecuária familiar na Metade Sul do Rio Grande do Sul. In: $2^{\circ}$ Encontro de Economia Gaúcha, 2004, Porto AlegreRS. Anais... Porto Alegre-RS: PUCRS, v. 1. p. 1-20, 2004.

FRANÇA, C. G.; DEL GROSSI, M. E.; MARQUES, V. P. M. A. O censo agropecuário 2006 e a agricultura familiar no Brasil. Brasília-DF: MDA, 2009. 96 p.

IBGE. Confronto dos resultados dos censos de 1970, 1996, 2006, 2010 e 2012 - Rio Grande do Sul. Disponível em: <http://www.sidra.ibge.gov.br/bda/>. Acesso em: 04 maio 2012.

IBGE. Levantamento e Classificação do Uso da Terra: Uso da Terra no Estado do Rio Grande do Sul. Relatório Técnico. Rio de Janeiro-RJ: IBGE, 2010.

INCRA. Instituto Nacional de Colonização e Reforma Agrária. Superintendência 11/RS. Relatório de Gestão do Exercício de 2012. Porto Alegre-RS. Disponível em: <http://www.incra.gov.br/index.php/servicos/publicacoes/relatorios/fil e/1533-superintendencia-regional-11-rio-grande-do-sul>. Acesso em: 09 jul. 2013.

INCRA. Instituto Nacional de Colonização e Reforma Agrária. Superintendência 11/RS. Relatório de Gestão do Exercício de 2010. Porto Alegre-RS. Disponível em: $<$ http://www.incra.gov.br/index.php/servicos/publicacoes/relatorios/fil e/708relatorio-de-gestao-2010-sr11-rs?start=20>. Acesso em: 18 nov. 2011.

IRGA. Instituto Rio-grandense do Arroz. Arroz irrigado no RS - Área, produção e rendimento. Porto Alegre - RS. 2011. Disponível em: <http://www.irga.rs.gov.br/uploads/ 1318871 736PRODARRS___serie_hi storica.pdf $>$. Acesso em: 07 maio 2012.

KOVALSKI, C. H. Documento técnico contendo análise econômica da produção de arroz ecológico em lote de Reforma Agrária, no Assentamento Novo Horizonte no município de Santa Margarida do Sul RS, no ano-safra 2009/2010. Disponível em: <http://www.iica.int/Esp/regiones/sur/brasil/Lists/DocumentosTecnico 
sAbertos / Attachments /323/Carlos\%20Henrique\%20Kovalski\%20>. Acesso em: 14 mar. 2012.

MDA. Ministério de Estado do Desenvolvimento Agrário. Portaria $n^{\circ} 7$ de 31 de Janeiro de 2013. Diário Oficial da República Federativa do Brasil, Brasília, DF, 01 de fevereiro de 2013.

MELLO, P. F. Módulo de assentamento para o Rio Grande do Sul. In: XLV Congresso da Sociedade Brasileira de Economia, Administração e Sociologia Rural (SOBER), 2007, Porto Alegre-RS. Anais... Disponível em: $<$ http://www.sober.org.br/palestra/6/164.pdf >. Acesso em: 12 mar. 2013.

MELO, R. W.; FONTANA, D. C.; BERLATO, M. A. Indicadores de produção de soja no Rio Grande do Sul comparados ao zoneamento agrícola. Pesquisa agropecuária brasileira, Brasília-DF, v. 39, n. 12, p. 11671175 , dez. 2004.

NABINGER, C.; FERREIRA, E. T.; FREITAS, A. K.; CARVALHO, P. C. F.; SANT'ANNA, D. M. Produção animal com base no campo nativo: aplicações de resultados de pesquisa. In: PILLAR, V. P. et al., (Org.) Campos Sulinos: Conservação e Uso Sustentável da Biodiversidade. Brasília: Ministério do Meio Ambiente, v.1, p. 175-198, 2009.

NETTO, C. G. A. M. O futuro dos Campos: possibilidades econômicas de continuidade da bovinocultura de corte no Rio Grande do Sul. In: PILLAR, V. P. et al., (Org.) Campos Sulinos: Conservação e Uso Sustentável da Biodiversidade. Brasília: Ministério do Meio Ambiente, v.1, p. 380-390, 2009.

OVERBECK, G. E. et al., Os Campos Sulinos: um bioma negligenciado. In: PILLAR, V. P. et al., (Org.) Campos Sulinos: Conservação e Uso Sustentável da Biodiversidade. Brasília: Ministério do Meio Ambiente, v.1, p. 175-198, 2009.

PICCIN, M. B. Os Senhores da Terra e da Guerra no Rio Grande do Sul: um estudo sobre as práticas de reprodução social do patronato rural estancieiro. 2012. 457 f. Tese (Doutorado em Ciências Sociais) Universidade Estadual de Campinas, Campinas. 2012. 
ROCHA, J. M. As Raízes da Crise da Metade Sul: Estudo da formação econômica do Rio grande do Sul. Jaguarão-RS: Fundação Universidade Federal do Pampa, 2011.

ROCHA, J. M.; ZANELLA, F. C.; CRUZ, R. C.; WENCESLAU, F. F. Sustentabilidade e Desenvolvimento nas Políticas dos Assentamentos Rurais da Metade Sul do Rio Grande do Sul. In: I Seminário de Desenvolvimento Regional, Estado e Sociedade (SEDRES), 2012, Rio de Janeiro-RJ. Anais... Rio de Janeiro-RJ: UFRJ, 2012.

Submetido em 24/09/2013

Aprovado em 24/06/2015

\section{Sobre os autores}

Jefferson Marçal da Rocha

Doutor em Meio Ambiente e Desenvolvimento. Professor Adjunto da Universidade Federal do Pampa. Bolsista Produtividade CNPq.

Endereço Avenida Antonio Trilha,1847 - II Piso, Centro. 97300000 - São Gabriel- RS Brasil.

E-mail: jeffersonrocha@unipampa.edu.br

Francis Casagranda Zanella

Acadêmico do Curso de Bacharelado em Gestão Ambiental - Universidade Federal do Pampa. Bolsista de Iniciação Científica PROBIC/Fapergs.

E-mail: franciszanella@gmail.com

\section{Rafael Cabral Cruz}

Doutor em Ecologia. Professor Adjunto da Universidade Federal do Pampa. Bolsista Extensão CNPq

E-mail: rafaelcruz@unipampa.edu.br 